\title{
Houve redução do impacto da indústria na economia brasileira no período 1996-2009? Uma análise das matrizes insumo-produto *
}

\author{
Luiza Nassif ** \\ Lucas Teixeira ${ }^{* * *}$ \\ Frederico Rocha ${ }^{* * * *}$
}

\begin{abstract}
Resumo
O presente artigo pretende adicionar nova evidência ao debate de desindustrialização da economia brasileira por meio de indicadores de encadeamentos para frente e para trás. Utilizam-se os índices de Rasmussen-Hirschman para a economia brasileira nos anos de 1996, 2000, 2005 e 2009. O artigo conclui que existe pouca evidência para sustentar a tese de que houve desindustrialização da economia brasileira no período. Durante o período não é observada nenhuma tendência de redução da participação da indústria de transformação em valor adicionado ou emprego total. Em relação aos índices de Rasmussen-Hirschman, os segmentos dentro da indústria de transformação experimentaram decréscimos entre 1996 e 2000 e a maior parte deles apresentou recuperação entre 2000 e 2009.
\end{abstract}

Palavras-chave: Desindustrialização; Indústria brasileira; Insumo-produto; Encadeamentos; Setores chave.

\section{Abstract \\ Was there a reduction in the impact of industrial sectors on the Brazilian economy between 1996 and 2009? An input-output analysis}

This aim of this paper is to add new evidence to the debate on the deindustrialization of the Brazilian economy by exploring indicators that measure backward and forward linkages. The paper uses the Rasmussen-Hirschman indexes for the Brazilian economy for the years 1996, 2000, 2005 and 2009. It is concluded that there is little evidence to hold the thesis that deindustrialization of the Brazilian economy has taken place. During the periods mentioned there was no clear trend of a fall in the manufacturing industry's share in gross added value or total employment. Furthermore, the RasmussenHirschman indexes for different sectors within the manufacturing industry show a reduction in backward and forward linkages between 1996 and 2000 and a recovery between 2000 and 2009.

Keywords: Deindustrialization; Brazilian industry; Input-output; Linkages; Key sectors.

JEL D57, L16, L60, O14, O54.

${ }^{*}$ Trabalho recebido em 14 de dezembro de 2013 e aprovado em 8 de maio de 2015.

*** Aluna de doutorado da The New School for Social Research, Nova Iorque, Estados Unidos. E-mail: pirel110@newschool.edu.

*** Economista do Banco Nacional de Desenvolvimento Econômico e Social (BNDES), Rio de Janeiro, RJ, Brasil. E-mail: lucas.teixeira@bndes.gov.br.

${ }^{* * * * *}$ Professor do Instituto de Economia da Universidade Federal do Rio de Janeiro (UFRJ), Rio de Janeiro, RJ, Brasil. E-mail: fred@ie.ufrj.br.

+ Os autores são gratos ao professor Fabio Freitas por comentários, sugestões e debates sobre o tema, eximindo-o, como de praxe, de responsabilidade sobre o conteúdo final. Frederico Rocha agradece ao CNPq por financiamento do projeto Universal "A integração comercial e produtiva da indústria brasileira em um mundo fragmentado”. Luiza Nassif agradece à Capes por financiamento de seu doutorado. 


\section{Introdução}

Há uma tradição econômica que destaca o papel da indústria como o motor do desenvolvimento de uma nação (Kaldor, 1978, Young, 1928, Rosenstein-Rodan, 1957, Hirschman, 1958). Essa tradição fundamenta a importância da indústria nas externalidades que esta pode gerar para os outros setores e, consequentemente, são patronos entusiastas de políticas econômicas que privilegiem a indústria para se alcançar o crescimento econômico de longo prazo. Mais especificamente, Hirschman argumenta que os encadeamentos para frente e para trás têm um papel central na defesa desta característica única da indústria.

Preocupados com as consequências de uma perda de capacidade da indústria de induzir crescimento, alguns acadêmicos e pesquisadores têm argumentado que o Brasil está passando por um processo de desindustrialização. De acordo com esta vertente da literatura, a desindustrialização da economia brasileira começou nos anos 1980, depois que o país terminou o ciclo de implementação da indústria pesada. Esse processo se aprofundou com as reformas do Consenso de Washington nos anos 1990 e continuou a se desenrolar por conta da valorização cambial recente (IEDI, 2005, 2007; Oreiro; Feijó 2010). Há, entretanto, autores que argumentam que há escassa evidência de ocorrência de um processo de desindustrialização (Nassif, 2008) e que evidências adicionais devem ser recolhidas para se caracterizar esse processo.

O objetivo do presente trabalho é acrescentar evidências para este debate, explorando medidas de encadeamentos para frente e para trás na economia brasileira. São utilizadas as matrizes de insumo-produto para se calcular os índices de encadeamento para frente e para trás e os índices de Rasmussen-Hirschman para os anos de 1996, 2000, 2005 e 2009. Propõe-se, aqui, a utilização desta medida como complemento às medidas tradicionais utilizadas para verificar a existência de um processo de desindustrialização. Ela pode ser utilizada como informação adicional para melhor caracterizar o processo pelo qual passa a indústria de um país, em um dado período.

O trabalho está organizado em mais quatro seções, além desta introdução. $\mathrm{Na}$ seção um, é apresentado o arcabouço analítico. A seção dois é dedicada à metodologia. Na seção três é empreendida a análise dos dados e, finalizando, as principais conclusões são apresentadas.

\section{Arcabouço analítico}

\section{Por que indústria?}

O debate presente na literatura sobre desindustrialização conduz ao questionamento sobre o que há de especial na indústria. Uma forma de apresentar as peculiaridades do setor industrial está sintetizada nas três leis de Kaldor (1978): (i) a relação positiva entre a taxa de crescimento do produto industrial e a taxa de 
crescimento do produto total (ii) a existência de uma relação positiva entre o crescimento da produtividade do trabalho da economia e o crescimento do produto industrial (lei de Kaldor-Verdoorn); e (iii) relação positiva entre a taxa de crescimento do produto industrial e a taxa de crescimento da produtividade nos demais setores da economia.

Estas leis, formuladas a partir de análise empírica, apontam para ganhos de produtividade inerentes à atividade industrial. Estes ganhos de produtividade estão relacionados à existência de economias de escala, estáticas e dinâmicas, pensadas como um fenômeno macro, como formulado por Kaldor (1978) e Young (1928). Para estes autores, tais economias não podem ser discriminadas adequadamente observando variações no tamanho de firmas individuais ou de setores industriais, porque podem ser originadas de externalidades e de spill-overs de outros setores. Caso as economias de escala tenham cessado em um determinado setor, este pode se beneficiar da expansão da produção nos demais setores da economia.

Sob esta perspectiva, o crescimento econômico passa a ser visto como um processo de causalidade cumulativa em que os ganhos de produtividade e a expansão do produto se retroalimentam. Tal mecanismo seria exclusivo da indústria e, em particular, da indústria de transformação. Indo além, podemos afirmar que tal mecanismo se desenvolve de forma mais intensa neste setor, pois é nele que temos uma estrutura de geração e difusão de inovações mais dinâmica.

Hirschman (1958) destaca o mesmo interesse pela indústria ao procurar identificar regras de investimento para o desenvolvimento em uma situação de crescimento desbalanceado. Ele propõe que, se um setor utiliza o produto de outro como insumo, o crescimento de um deles traz incentivos para o investimento no outro. Essa relação intrassetorial pode produzir dois efeitos. O primeiro é um efeito de demanda, que ocorre quando o setor localizado a jusante utiliza como insumo um produto do setor a montante. O crescimento do primeiro setor aumenta a demanda pelo produto do segundo, induzindo o seu crescimento. Esse efeito é chamado por Hirschman de backward linkage ou encadeamento para trás.

Em contrapartida, o crescimento do setor a montante também poderia gerar economias externas aumentando a produtividade no setor a jusante. Um aumento da produtividade do setor a montante gera um ganho potencial de produtividade sobre o setor a jusante que utiliza tal produto como insumo. Esse segundo efeito é definido como forward linkage ou encadeamento para frente.

O backward linkage possui um efeito mais direto, pois exerce uma pressão sobre a indústria para fornecer mais insumos. Em um primeiro momento, a demanda criada pelo insumo poderia ser suprida por importações, mas há oportunidade de desenvolvimento de processos a montante para prover insumos. Dessa forma, quando setores com alto grau de efeitos de encadeamento para trás crescem, a 
produção interna de seus insumos é incentivada. O forward linkage, por sua vez, pode ser descrito como um estímulo a prosseguir na cadeia produtiva. Hirschman defende que a probabilidade de que esse estímulo resulte de fato em investimento depende da importância que o produto do setor que cresce tem sobre o setor a ser encadeado.

Portanto, setores que se encontram na base da cadeia produtiva, como agricultura e extrativismo, terão baixo poder de encadeamento para trás, mas poderão possuir encadeamentos para frente ${ }^{1}$. Setores produtores de bens finais, por sua vez, apresentarão alto backward linkage e baixo forward linkages. No caso das atividades industriais que se encontram no meio da cadeia, os incentivos tanto para trás quanto para frente devem ser altos.

Ao longo de um processo de industrialização, os entroncamentos entre as atividades devem aumentar. Backward e forward linkages crescem de acordo com o nível de industrialização, pois ocorre um efeito multiplicador intersetorial. À medida que um setor cresce, seus encadeamentos são responsáveis por incentivos ao investimento nas atividades produtivas conexas.

A partir dessa análise, Hirschman considera que um processo de industrialização cria uma alimentação circular a partir dos encadeamentos. Portanto, ao passo que as atividades industriais ganham participação na economia, seus encadeamentos crescem e incentivam ainda mais seu crescimento. Seguindo tal argumento, ao pensarmos em um processo precoce de desindustrialização, um dos sinais aparentes será a queda de encadeamentos nos setores industriais. O processo de alimentação circular deixaria de funcionar e um enfraquecimento dos encadeamentos poderia ser verificado.

Nessa linha de argumentação, há três ponderações a serem feitas. A primeira diz respeito à contínua possibilidade de aprofundamento dos elos das cadeias produtivas. Está claro que existe um limite para o estabelecimento de elos internos às cadeias e que ganhos a partir desse processo tendem a ser limitados no tempo (ver Syrquin, 1988, a respeito da evolução dos ganhos decrescentes da participação da indústria a partir das relações insumo-produto). A segunda ponderação está associada às distintas participações dos diferentes setores no processo de encadeamento. Rocha (1998) explora as possibilidades de crescimento do setor de serviços pela maior participação relativa dos serviços intermediários. Esse fator pode ter relevância, tanto pelo ponto de vista contábil, vide a externação de atividades antes presentes dentro da indústria, como também pela criação de valor a partir de novas atividades de serviços ou, até mesmo, pelo aprofundamento ou ganho de

(1) Os encadeamentos para trás, nesse caso, serão referentes a tecnologias utilizadas, como máquinas e equipamentos. Nesse caso, fica claro que em uma economia mais industrializada é possível perceber um backward linkage maior, inclusive nas atividades primárias. 
importância relativa de algumas atividades como, por exemplo, telecomunicações (ver Nassif, 2013). A terceira linha de ponderação é a localização de distintas etapas produtivas no âmbito das cadeias globais de valor. Nesse caso, porém, o foco estaria na mudança do entendimento do papel dos encadeamentos na divisão internacional do trabalho.

\section{O debate sobre desindustrialização e suas controvérsias}

Seguindo a ideia de Rowthorn e Ramaswany (1997 e 1999), podemos separar os fatores causadores de desindustrialização entre internos ou externos e, ainda entre estes, distinguir se são fatores que atuam pelo lado da oferta ou pelo lado da demanda. Como bem apontam Rowthorn e Wells (1987), nem todo processo de desindustrialização é necessariamente algo negativo, significando o fracasso da indústria. Ele pode ser o alcance da maturidade de uma economia desenvolvida ou, ainda, a especialização da economia em algum outro setor.

Dos fatores internos, que atuam pelo lado demanda, temos aqueles primeiramente apontados por Colin Clark, ainda nos anos 1950. Para Clark (1957), o processo de desenvolvimento de um país seria marcado primeiramente por um aumento da participação do setor industrial, ao custo de uma redução da participação do setor primário. E, posteriormente, a participação do setor industrial reduziria, com um aumento da participação do setor de serviços, seja medida em termos de participação no produto, seja por mão de obra empregada em cada setor. Isso seria um processo normal em economias industriais maduras que atingem elevados níveis de renda per capita, cuja causa seria alterações nas elasticidades-rendas da demanda por produtos primários, industrializados e por serviços (seguindo o caminho apontado pela lei de Engel). Observa-se, desta forma, a trajetória de amadurecimento de uma economia industrial, conduzida por um processo bem definido de mudanças na composição da demanda.

Baumol (1967), apesar de preocupado com outras questões que não estritamente a desindustrialização, fornece os elementos básicos para se compreender os fatores pelo lado da oferta que conduzem a esse processo. De acordo com Baumol, haveria dois tipos de setores na economia: um setor dinâmico, que apresenta ganhos sistemáticos de produtividade do trabalho, e um setor estagnado, cuja produtividade do trabalho não apresenta tendência de crescimento. Desconsiderando mudanças na composição da demanda, a proporção de mão de obra empregada no setor dinâmico tenderia a reduzir a favor do setor estagnado; a composição do produto em termos reais não se alteraria, mas a parcela do setor dinâmico cairia, se medida a preços correntes. Como para o autor o setor dinâmico é a indústria manufatureira e o setor estagnado é o de serviços, seu modelo de crescimento "desbalanceado" serve como um modelo de desindustrialização, 
conduzido por fatores de oferta. Este tipo de análise foi posteriormente melhor desenvolvido por outros autores, como Rowthorn e Wells (1987).

Outros estudos, no entanto, apontaram fatores ligados ao comércio exterior. Sachs e Schatz (1994) e Saeger (1996) apontam para o crescimento do comércio norte-sul. Os países desenvolvidos importariam bens manufaturados intensivos em trabalho dos países em desenvolvimento, o que deslocaria a produção dos países desenvolvidos em direção a bens menos intensivos em mão de obra. Ainda poderia haver o caso de doença holandesa, como indica Palma (2005), no qual a descoberta de um recurso natural com elevados preços e demanda no mercado internacional causaria uma profunda valorização cambial, que tornaria o país não competitivo em todos os outros setores produtores de tradables, levando a uma especialização da economia no setor produtor de commodities.

O debate atual sobre desindustrialização em países em desenvolvimento, em geral, e no Brasil, em particular, concede a este fenômeno um caráter eminentemente negativo ${ }^{2}$. Palma (2005) analisa a relação na forma de "U" invertido entre renda per capita e mão de obra empregada na indústria. O que chama atenção do autor, é que a desindustrialização estaria acontecendo a níveis de renda per capita cada vez mais baixos. As economias estariam perdendo o motor do desenvolvimento econômico antes de se tornarem desenvolvidas.

Para elucidar tal acontecimento, o autor recorre a uma explicação ad hoc: reformula o conceito de doença holandesa para associar a redução da proporção do emprego industrial no total de empregados às reformas estruturais implementadas na América Latina nos anos 1990 (popularmente conhecidas como Consenso de Washington). Reformas estas que teriam levado a uma especialização dessas economias em suas vantagens comparativas, apontado pelo autor como um "padrão 'ricardiano' rico em recursos naturais" (Palma, 2005).

Para Bresser-Pereira (2008), o Brasil (assim como o México) sempre foi sujeito à doença holandesa, mas conseguiu neutralizá-la de forma efetiva entre 1930 e 1980, por meio de taxas múltiplas de câmbio, sistema de tarifas e subsídios ao comércio exterior e outras medidas de política econômica. A neutralização permitiu o investimento nos setores produtores de bens comercializáveis, que não floresceriam em contexto de doença holandesa, conduzindo ao processo de industrialização e ao rápido crescimento característicos do período. Para o autor, a doença começou a se manifestar no período 1990-1992 com a abertura comercial e financeira, e se agravou no início dos anos 2000, com o boom internacional dos

(2) Palma (2005) não foi o primeiro a ver a desindustrialização como algo negativo. Kaldor (1978), por exemplo, explica o fraco desempenho da economia britânica pelo também fraco desempenho da indústria manufatureira. Para Kaldor, a indústria havia perdido a sua capacidade de liderar o crescimento econômico antes de se atingir elevado patamar de desenvolvimento, comparando-se a renda per capita inglesa com a norte-americana. 
preços de commodities causadas, em grande parte, pela demanda chinesa. Os sintomas seriam, além da sobreapreciação cambial, baixo crescimento da indústria manufatureira, crescimento do setor terciário e desemprego, caracterizando uma desindustrialização prematura.

Nassif (2008) parte da análise da produtividade do trabalho na indústria e do peso da indústria de transformação no produto. Deste ponto de vista, discorda das interpretações que apontam para a ocorrência de desindustrialização, pois o setor industrial teria conseguido manter sua participação no produto total durante os anos 1990. Localiza alguma redução neste indicador nos anos 1980, antes das reformas estruturais dos anos 1990, indo, portanto, de encontro à abordagem da desindustrialização via doença holandesa, como definida por Palma (2005) e Bresser-Pereira (2008). Além disso, analisando a partir dos dados da Pesquisa Industrial Anual (PIA) do IBGE, não se verificam mudanças relativas significativas nos setores industriais, exceto o de refino de petróleo.

Nassif (2008), ademais, não corrobora a análise de Laplane e Sarti (2006), de que haveria ocorrido ganhos substanciais de produtividade do trabalho na indústria nos anos 1990. Para estes autores, tais ganhos podem ser verificados a partir do crescimento da produção física concomitante a uma queda (ou baixo crescimento, dependendo do ano) do emprego industrial. Nassif chega a conclusão de que não houve ganhos substanciais de produtividade, por meio da análise do valor agregado na indústria em relação ao pessoal ocupado. O problema deste indicador, no entanto, reside na forma como o valor agregado é calculado, pois este é um dado residual, obtido pela diferença entre o valor do produto final e dos custos da produção. Ao se deflacionar este resultado, pode-se perder informações relevantes sobre variações de preços relativos entre o produto industrial e seus insumos, que poderiam indicar mudanças na produtividade do setor. O caminho do meio parece estar em Rocha (2007) que, por meio de uma análise de shift-share para a variação da produtividade do trabalho no período 1970-2001, observa crescimento apenas moderado da produtividade do trabalho na indústria na segunda metade dos anos 1990.

IEDI (2005) afirma que o processo de desindustrialização da economia brasileira iniciou-se nos anos 1980, fruto da inflação alta e crônica e das políticas anti-inflacionárias empreendidas no período, seguiu nos anos 1990 com a abertura econômica e a apreciação cambial e apenas é interrompido a partir de 1999, com a mudança de regime cambial. A principal conclusão do texto é que houve uma desindustrialização "relativa", pois a indústria de transformação reduziu sua participação no PIB (e, de forma menos intensa, no emprego total), perdeu elos e cadeias significativos, porém manteve uma expressiva diversificação e preservou atuação em todos os setores considerados básicos, de acordo com a classificação tecnológica. Não houve, portanto, uma perda irreparável no setor industrial, de forma que este pôde reerguer-se e voltar a liderar o crescimento e desenvolvimento 
econômico. IEDI (2007), no entanto, vai além, afirmando que a desindustrialização estaria se ampliando no Brasil, tendo como causa a política de juros elevados então praticada, que inibia o investimento e o gasto público e valorizava o câmbio, reduzindo a competitividade das exportações brasileiras e propiciando a substituição de produção doméstica por importações.

Oreiro e Feijó (2010) concordam com as exposições de que houve desindustrialização nas décadas de 1980 e 1990, porém afirmam que este processo prosseguiu mesmo após a mudança no regime cambial em 1999 (como sustenta IEDI em 2007, ao contrário da sua posição em 2005). Chegam a essa conclusão pela comparação entre a taxa de crescimento do PIB e a taxa de crescimento do valor adicionado na indústria nos anos 2000. Verificaram que, sistematicamente, esta ficou abaixo daquela e, além disso, este movimento foi contemporâneo a uma significativa apreciação do câmbio real. Constatam também, como outros autores anteriormente citados, que a indústria de transformação perdeu participação no PIB, medindo-se a preços constantes. Para explicar a origem desse processo, apoiam-se nas teses de Palma (2005) e Bresser-Pereira (2008) que apontam para ocorrência de doença holandesa.

Percebe-se, assim, que o debate sobre o processo de desindustrialização no Brasil tem estado pouco focado nos processos de encadeamento e organização da indústria. Uma análise mais aprofundada sobre a redução e quebra de elos e sobre a criação de novas atividades se faz necessária.

\section{Metodologia}

Trabalhamos com as matrizes brasileiras de impactos diretos e indiretos intersetoriais de 1996, 2000, 2005 e 2009. O IBGE disponibiliza as matrizes de 1996 a 2005 de acordo com três agregações setoriais. Em uma delas, disponível para todos os anos, a agregação é composta por 12 setores. Até o ano de 1996, a agregação mais ampla do IBGE incluía 43 setores no nível 80. A partir dos anos 2000, essa agregação passou a conter 55 setores, utilizando a CNAE 1.0. Para o trabalho empírico apresentado a seguir, foi necessário compatibilizar as duas classificações, o que resultou em uma classificação com 22 setores (ver apêndice). A matriz de 2009 foi obtida de Freitas et al (2012) e também adaptada ao sistema de 22 setores.

Para cada setor, a cada ano, foram calculados o Backward Linkage (BL), o Foward Linkage (FL) e os índices de Rasmussen-Hirschman, Power of dispersion (PD) e Sensibility of Dispersion (SD).

Analisando a matriz insumo-produto, os backward linkages podem ser interpretados como o impacto do aumento unitário na demanda final da atividade sobre a produção na economia como um todo. Os forward linkages, por sua vez, 
podem ser interpretados como o aumento na produção da atividade quando há um aumento unitário na demanda final de todos os setores da economia.

Seja $A$ a matriz dos coeficientes técnicos diretos:

$$
A=\left[\begin{array}{ccc}
a_{1,1} & \cdots & a_{1,22} \\
\vdots & \ddots & \vdots \\
a_{22,1} & \cdots & a_{22,22}
\end{array}\right]
$$

onde cada elemento $a_{i j}$ é o valor produzido no setor i e consumido pelo setor j para se produzir uma unidade monetária, representando um coeficiente técnico direto de produção do setor $\mathrm{j}$.

A matriz $Z$, por sua vez, é a matriz de Leontief, ou matriz dos coeficientes técnicos diretos e indiretos:

$$
Z=(I-A)^{-1}=\left[\begin{array}{ccc}
z_{1,1} & \cdots & z_{1,22} \\
\vdots & \ddots & \vdots \\
z_{22,1} & \cdots & z_{22,22}
\end{array}\right]
$$

onde cada elemento $z_{i j}$ pode ser interpretado como o impulso direto e indireto de uma variação unitária na demanda pela produção da atividade j sobre a produção do setor $\mathrm{i}$, representando o coeficiente técnico direto e indireto do setor j sobre o setor i.

Seja $z_{i j}$ o elemento da linha i e coluna j da matriz de impactos diretos e indiretos, o backward linkage (BL) do setor j é calculado da seguinte forma:

$$
B L_{j}=\sum_{i=1}^{22} z_{i j}
$$

e o forward linkage (FL) do setor i é calculado da seguinte forma:

$$
F L_{i}=\sum_{j=1}^{22} z_{i j}
$$

O poder de dispersão (PD), associado aos backward linkages, indica a ordem da grandeza do impacto de uma variação na demanda final pela atividade $\mathrm{j}$ sobre seus fornecedores. Se este índice for superior à unidade, uma variação na demanda final do setor gera uma compra de insumos acima da média na economia, o que releva fortes encadeamentos para trás no sistema produtivo.

A sensibilidade de dispersão (SD), associada aos forward linkages, indica a sensibilidade da produção do setor i a um aumento unitário da demanda final em 
todos os setores. Se for maior que a unidade, o índice mostra que, diante de uma variação na demanda final de todas as atividades econômicas, a produção do setor aumenta acima da média na economia. Tal fato indica uma dependência do setor acima da média em relação à produção de outros setores, uma vez que se destaca como forte fornecedor de insumos.

Seja $Z^{*}$ a média de todos os elementos da matriz de impactos diretos e indiretos, e $n$ o número de linhas e colunas da matriz, os índices de RasmussenHirchsman são calculados da seguinte forma:

$$
P D_{j}=\frac{\left(B L_{j} / n\right)}{Z^{*}} \quad \text { e } \quad S D_{i}=\frac{\left(F L_{i} / n\right)}{Z^{*}}
$$

\section{Análise empírica}

Uma das maneiras usuais de se mensurar a mudança estrutural e verificar a existência de desindustrialização é por intermédio da análise da evolução da participação do valor adicionado e do emprego industriais no total da economia. A figura 1 apresenta essas duas séries para a indústria de transformação para o período de 1996 a 2009. Se algo pode ser extraído das duas séries é a sua relativa estabilidade. Em 1996, a indústria representava 16,8\% do valor adicionado total e, em 2009, 16,6\%. O valor mínimo dessa série é alcançado em 1998, quando a participação da indústria chegou a 15,8\% do valor adicionado total, e o valor máximo foi alcançado em 2004, quando a participação da indústria alcançou 19,2\%. Muitos defensores da tese da desindustrialização se baseiam na trajetória decrescente entre o ápice da série e 2009 para argumentar pela existência de uma tendência ${ }^{3}$ (Oreiro; Feijó, 2010). Pela trajetória apresentada na série de flutuação e pelo movimento cíclico encontrado, a conclusão de desindustrialização parece ser um pouco precipitada.

O uso de séries de valor adicionado pode, no entanto, gerar vieses que fazem com que uma parte significativa dos autores deem preferência à série de emprego (Syrquin, 1988; Rocha, 2007). O primeiro problema surge pela forma de cálculo do valor adicionado em que uma parcela substantiva, o excedente operacional bruto, é definido por resíduo. O segundo está associado ao comportamento dos rendimentos do trabalho que pode ser errático e variar entre os setores. O terceiro, e talvez mais importante, são os movimentos de preços relativos. Esses movimentos são de difícil captação e mesmo a utilização de índices de preços pode conduzir a vieses ${ }^{4}$. A

(3) Algumas exceções a essa interpretação foram apresentadas anteriormente. Bresser-Pereira (2008) afirma que o início desse processo se deu nos anos 1990 e IEDI (2005) o localiza nos anos 1980.

(4) No caso brasileiro, o índice de preços mais utilizado é o IPA-OG setorial. O IPA-OG tem importante influência do câmbio que pode acabar em um viés importante. Uma alternativa seria o uso de um sistema de deflatores a partir de séries de produção. Esse sistema pode ser interessante para a indústria, mas encontra sérios obstáculos nos serviços, em que a unidade de mensuração do produto não é bem definida. 
observação da série de emprego apresenta ainda maior estabilidade. O início da série apresenta uma participação de $12,8 \%$ e o final de $12,7 \%$. O valor mínimo alcançado é de 11,6\%, em 1998, e o máximo, 13\%, em 2008. Essas duas séries nos conduzem, portanto, a pensar que a ocorrência de desindustrialização pode ser verdadeira, mas é anterior a 1996, conforme sugerido em IEDI (2005).

Figura 1

Evolução da participação da indústria de transformação no valor adicionado e no emprego da economia, Brasil, 1996-2009

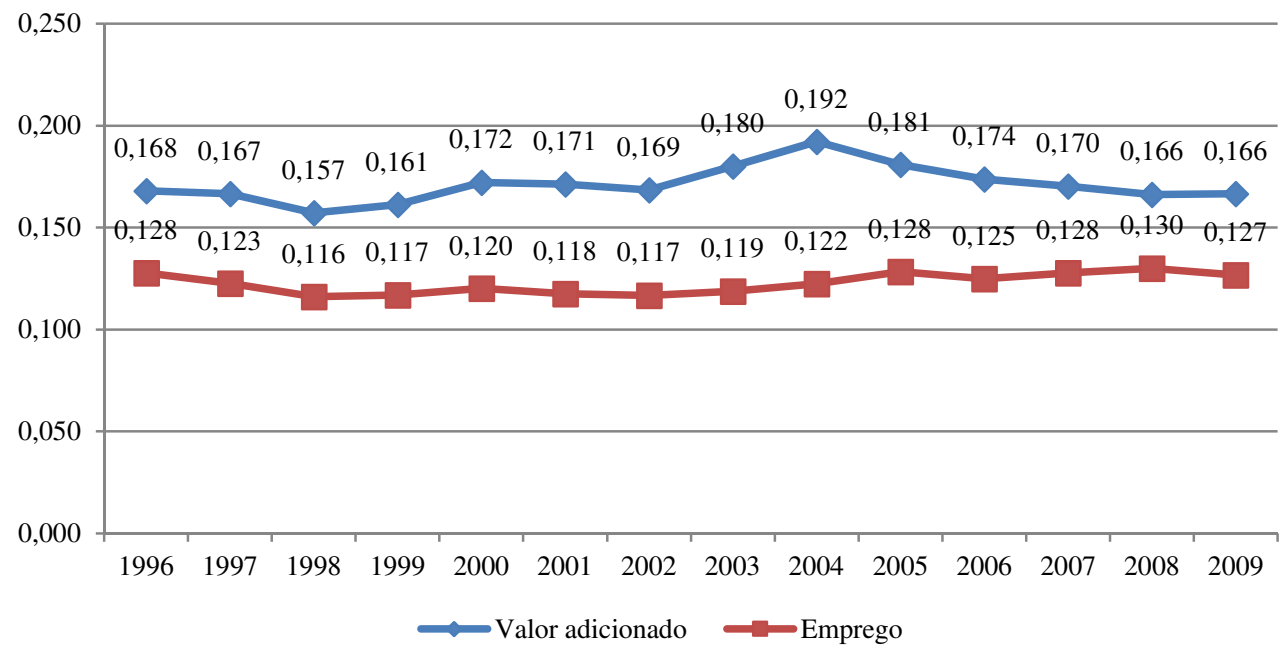

Fonte: IBGE, Sistema de Contas Nacionais, vários anos.

No entanto, os argumentos da desindustrialização não estão somente associados à perda da participação no valor adicionado e no emprego, mas também à forma como a indústria se desenvolve. Dois problemas adicionais são ressaltados (IEDI 2007). O primeiro é a mudança intrassetorial, ou seja, interna à indústria de transformação. Nesse caso, argumenta-se que os setores mais intensivos em conhecimento, que agregam mais valor, estariam perdendo espaço na indústria. Ainda que fora do objetivo deste trabalho, esse argumento não parece ser verificável nas séries de valor adicionado e de emprego e se sustenta apenas para as séries de comércio. É interessante observar, no entanto, que quando examinamos as séries de importações, a distribuição das importações entre os setores é caracterizada também pela estabilidade ${ }^{5}$. É no segundo argumento que este trabalho procura apresentar uma

(5) Os dados apresentados no mesmo trabalho do IEDI (2007) parecem dar suporte a essa interpretação. No período 1996-2000, a participação do VTI da indústria considerada de alta tecnologia aumenta em cerca de 6 pontos percentuais, para, posteriormente, reduzir em apenas 1 p.p. Enquanto o segmento que mais perdeu participação foi o de baixa intensidade tecnológica (IEDI, 2007, p. 15). E, mais adiante, os autores ainda qualificam que as mudanças dentro de cada segmento, ao analisar os dados de comércio exterior, parecem estar mais relacionadas ao comportamento das importações do que das exportações (Idem, p. 16). 
contribuição. $\mathrm{O}$ argumento se baseia na ideia de que há um crescimento na importação de bens intermediários da indústria e que este crescimento causa uma perda de densidade dos encadeamentos setoriais, retirando parte do poder da indústria de gerar valor. A maior parte desta argumentação está baseada na observação da razão entre valor adicionado e valor bruto da produção, apresentada na Figura 2. A perda de participação poderia indicar que produtos importados substituíram produtos nacionais no consumo intermediário e, portanto, o valor adicionado total da indústria pode ter se reduzido. Conforme apontado nessa figura, há uma redução nessa razão ao longo do tempo, podendo, neste caso, caracterizar uma tendência. Ainda que seja tentador explicar a queda da razão pelo crescimento das importações, os dados colhidos da matriz insumo-produto não parecem contribuir para a tese. A figura 3 apresenta o índice de penetração das importações para quatro anos. Certamente, as importações devem ter representado um papel relevante na redução da razão entre valor adicionado e valor bruto da produção entre 1996 e 2000, mas, a partir de então, não há uma direção clara no indicador de penetração das importações.

\section{Figura 2}

Evolução da razão valor adicionado/valor bruto da produção na indústria de transformação, Brasil, 1996-2009

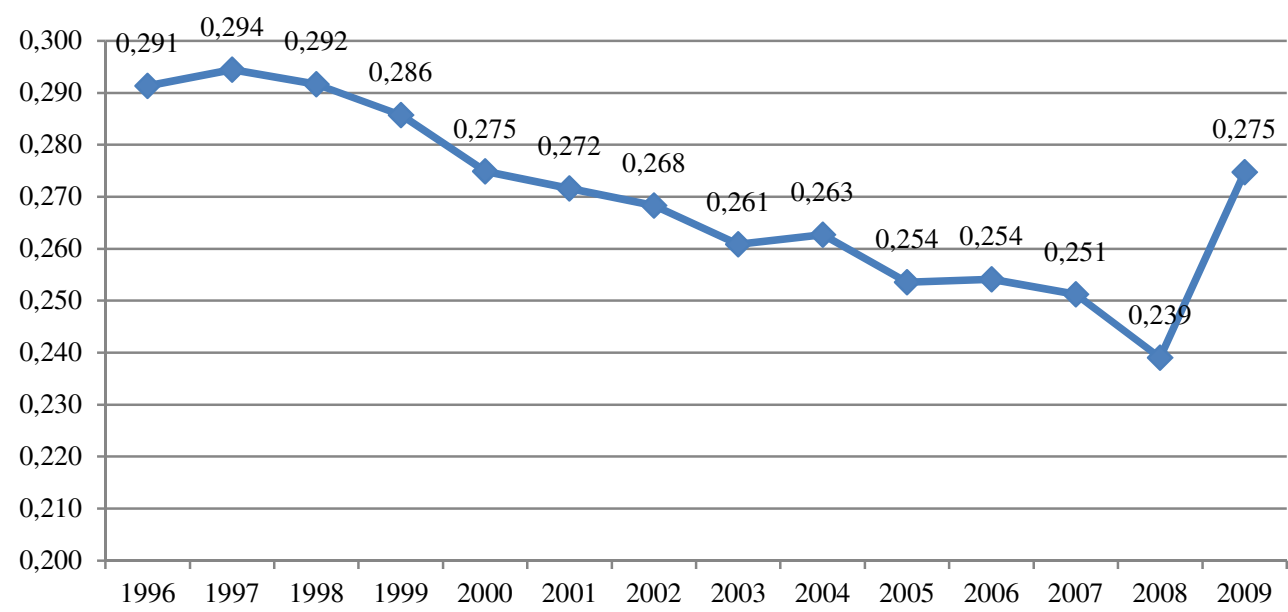

Fonte: IBGE, Sistema de Contas Nacionais, vários anos.

Conforme ressaltado em IEDI (2007), existem outras possíveis causas de redução desta razão. A primeira é o movimento de preços relativos que parece estar em todo o lugar, criando vieses, algumas vezes não identificados, para a análise. Neste caso, a alta do crescimento dos preços das commodities, produzidas em setores localizados na base da indústria, poderia estar influenciando o resultado. Este fenômeno tende a ser importante a partir da segunda metade da primeira década deste 
século, mais particularmente a partir de 2004, quando há uma aceleração no crescimento dos preços das commodities. A segunda causa seria o deslocamento de atividades antes realizadas na indústria de transformação para os serviços. Neste caso, o fenômeno é puramente contábil e pode ser conducente da desindustrialização sem representar fortes desequilíbrios dinâmicos para a economia. Este processo foi importante durante a década de 90 , mas não parece ter persistido posteriormente, de maneira que não explicaria a integralidade da série. Os serviços podem também influenciar a redução da razão valor adicionado-valor bruto da produção por uma terceira causa: mudança tecnológica. Neste caso, o surgimento de novos serviços intermediários pode incrementar o consumo intermediário da indústria, alterando a razão, mas sem alterar o valor adicionado na economia brasileira como um todo. De fato, alguns autores entendem que uma importante razão para a identificação de desindustrialização nos países centrais é a crescente incorporação de conteúdos de serviços na produção de bens industriais (ver Gershuny, 1987; Rocha, 1992). A figura 4 apresenta alguns dados que deixam perceber que há um forte crescimento do consumo intermediário de serviços pela indústria entre 1996 e 2000. Esse ganho de participação dos serviços no consumo intermediário da indústria é mantido ao longo do período. Tal fato aponta para um permanente aumento do encadeamento indústria-serviços.

\section{Figura 3}

Penetração das importações em segmentos da indústria de transformação,

Brasil, 1996, 2000, 2005, 2009*

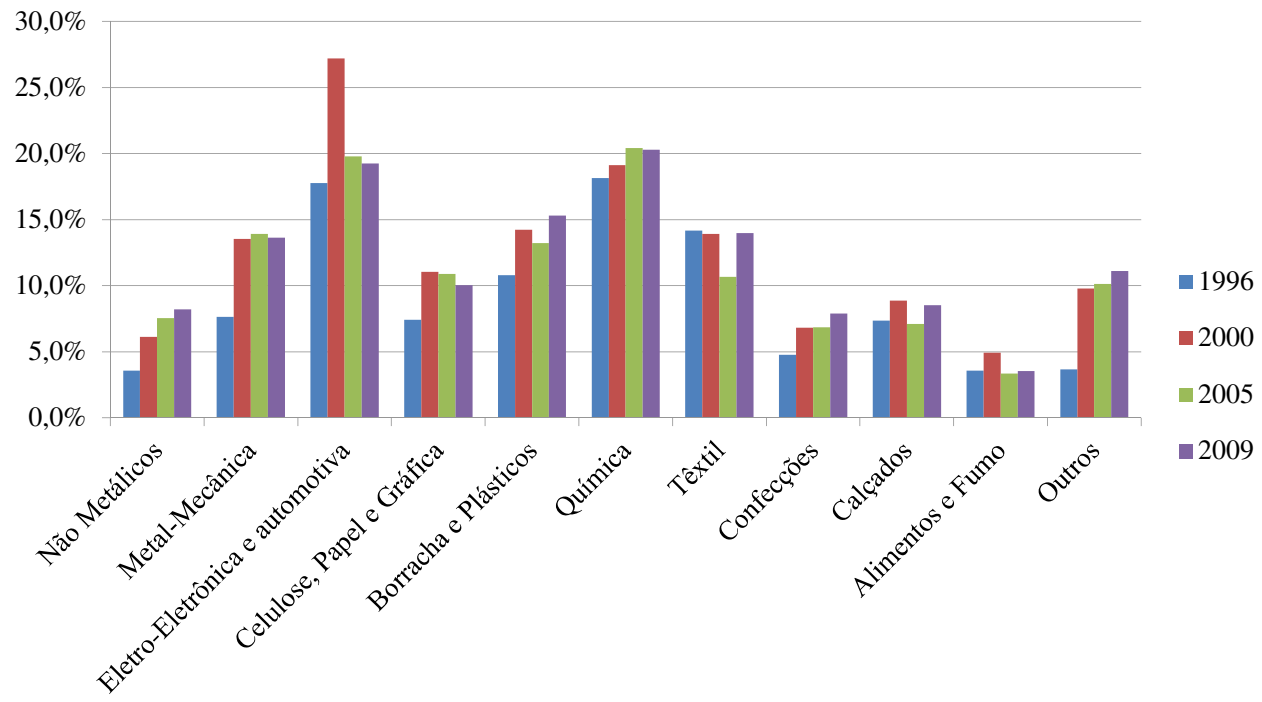

*O ano de 2009 foi estimado utilizando a metodologia desenvolvida por Freitas et al. (2012).

Fonte: IBGE, Matriz Insumo-Produto, 1996, 2000, 2005 e Freitas et al. (2012). 
Essas avaliações clamam por uma análise mais precisa dos efeitos sobre os encadeamentos da indústria na economia brasileira a partir de sua mensuração direta, conforme exposta na metodologia. Assim, se os defensores da tese de desindustrialização a partir da rarefação dos encadeamentos industriais e da perda de sua função de motor da economia estiverem corretos, será verificada uma redução dos encadeamentos ao longo do tempo.

Figura 4

Somatório dos coeficientes técnicos de consumo intermediário de serviços para os setores da indústria de transformação, Brasil, 1996, 2000, 2005 e 2009*

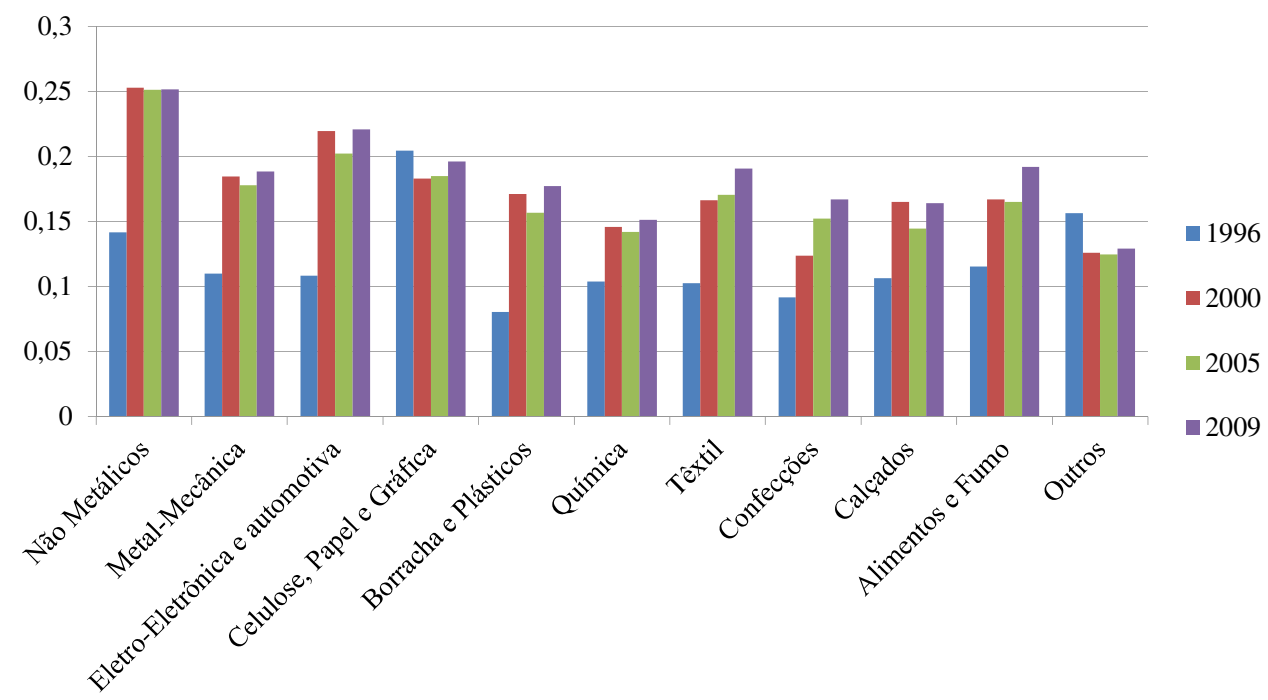

* O ano de 2009 foi estimado utilizando a metodologia desenvolvida por Freitas et al. (2012).

Fonte: IBGE, Matriz Insumo-Produto, 1996, 2000, 2005 e Freitas et al. (2012).

Uma primeira forma de se examinar o problema é verificar se a indústria permanece como uma importante geradora de demanda na economia brasileira. A Tabela 1 apresenta o poder de dispersão para anos selecionados no período de 1996 a 2009. Em todos os anos, o poder de dispersão dos segmentos da indústria de transformação é maior do que um e, antes de 2005, nenhum outro setor mantém poder de dispersão superior a um (em 2005, a indústria extrativa mineral também atinge valor superior a um). Assim, pode-se afirmar que a indústria de transformação permanece, durante o período, como o segmento de maior poder de encadeamento para trás na economia brasileira.

Com respeito à sensibilidade de dispersão, a indústria de transformação apresenta menor importância, quando comparada com outros segmentos. No entanto, dois setores da indústria de transformação permanecem com sensibilidade de dispersão superior a um em todo o período: metal-mecânica e química. A indústria têxtil tem esse indicador superior a um apenas em 1996. 
Tabela 1

Indicadores de poder de dispersão e sensibilidade de dispersão,

Brasil, 1996, 2000, 2005, 2009*

\begin{tabular}{|c|c|c|c|c|c|c|c|c|}
\hline & \multicolumn{4}{|c|}{ Poder de Dispersão } & \multicolumn{4}{|c|}{ Sensibilidade de Dispersão } \\
\hline & 1996 & 2000 & 2005 & 2009 & 1996 & 2000 & 2005 & 2009 \\
\hline Agropecuária & 0.9083 & 0.9175 & 0.9753 & 0,9561 & 1.4261 & 1.1165 & 1.1696 & 1,1775 \\
\hline Indústria extrativa mineral & 0.9981 & 0.9838 & 1.012 & 1,0282 & 0.8204 & 0.9857 & 1.1195 & 1,0401 \\
\hline Não Metálicos & 1.1296 & 1.118 & 1.095 & 1,1073 & 0.8293 & 0.7053 & 0.6976 & 0,7381 \\
\hline Metal-Mecânica & 1.1647 & 1.1056 & 1.1122 & 1,1094 & 1.6873 & 1.1838 & 1.2839 & 1,2538 \\
\hline $\begin{array}{l}\text { Eletro-Eletrônica } \\
\text { Automotiva }\end{array}$ & 1.1317 & 1.0881 & 1.1952 & 1,1900 & 0.8569 & 0.8667 & 0.9238 & 0,9359 \\
\hline Celulose, Papel e Gráfica & 1.2083 & 1.0487 & 1.0725 & 1,0598 & 0.981 & 0.9647 & 0.8612 & 0,8422 \\
\hline Borracha e Plásticos & 1.1118 & 1.2014 & 1.1731 & 1,1134 & 0.9373 & 0.8104 & 0.8059 & 0,7949 \\
\hline Química & 1.0729 & 1.1667 & 1.1553 & 1,1252 & 2.1619 & 2.0536 & 2.1604 & 1,9161 \\
\hline Têxtil & 1.2253 & 1.0596 & 1.0463 & 1,0413 & 1.3021 & 0.9855 & 0.9558 & 0,9044 \\
\hline Confecções & 1.2156 & 1.0191 & 1.0456 & 1,0233 & 0.5531 & 0.5677 & 0.5483 & 0,5602 \\
\hline Calçados & 1.2043 & 1.2631 & 1.2392 & 1,1383 & 0.6612 & 0.6864 & 0.6915 & 0,6611 \\
\hline Alimentos e Fumo & 1.3004 & 1.2808 & 1.3023 & 1,3223 & 0.9706 & 0.9441 & 0.9658 & 0,9512 \\
\hline Outros & 1.0912 & 1.014 & 1.0307 & 1,0068 & 0.7259 & 0.7086 & 0.6956 & 0,6973 \\
\hline $\begin{array}{l}\text { Produção e distribuição de } \\
\text { eletricidade, gás e água }\end{array}$ & 0.8611 & 0.9341 & 0.9231 & 0,9721 & 1.1217 & 1.2388 & 1.3122 & 1,2293 \\
\hline Construção & 0.8723 & 0.9678 & 0.9091 & 0,9456 & 0.6431 & 0.6434 & 0.6208 & 0,6407 \\
\hline Comércio & 0.9023 & 0.7681 & 0.7647 & 0,7747 & 1.1676 & 1.2953 & 1.2994 & 1,3960 \\
\hline $\begin{array}{l}\text { Transporte, armazenagem } \\
\text { e correio }\end{array}$ & 0.9594 & 0.9405 & 0.985 & 1,0061 & 1.0041 & 1.2364 & 1.2586 & 1,3212 \\
\hline Serviços de informação & 0.6935 & 0.9192 & 0.9026 & 0,9624 & 0.694 & 1.0068 & 1.0296 & 1,0360 \\
\hline Intermediação financeira & 0.7676 & 0.9057 & 0.7864 & 0,8055 & 0.8493 & 1.1652 & 1.0387 & 1,1968 \\
\hline $\begin{array}{l}\text { Atividades imobiliárias e } \\
\text { aluguel }\end{array}$ & 0.581 & 0.5819 & 0.5785 & 0,6084 & 0.692 & 0.6743 & 0.6459 & 0,6754 \\
\hline Outros serviços & 0.8259 & 0.9024 & 0.8864 & 0,8922 & 1.2012 & 1.5523 & 1.3309 & 1,4367 \\
\hline $\begin{array}{l}\text { Administração, saúde e } \\
\text { educação públicas }\end{array}$ & 0.7747 & 0.8137 & 0.8095 & 0,8116 & 0.7139 & 0.6084 & 0.5849 & 0,5950 \\
\hline
\end{tabular}

Setores com valores de sensibilidade de dispersão e poder de dispersão superiores a um são conhecidos como os setores chave de uma economia. Assim, há uma mudança nos setores chave da economia brasileira ao longo dos doze anos da análise. No início do período, metal-mecânica, química e têxtil são os setores chave e, no final do período, metal-mecânica, química, indústria extrativa mineral e transporte, armazenagem e correio ocupam essa posição (ver Quadro 1). Aparentemente, existe nessa mudança uma tendência de a indústria de transformação 
caminhar na direção de segmentos mais da base. No entanto, não se pode afirmar com isso que são de menor intensidade tecnológica (hipótese não testada neste trabalho). Uma possível interpretação para essa mudança pode ser que o cenário de abertura comercial vem organizando as economias nacionais de acordo com sua dotação inicial de fatores. Assim, o país passa a abandonar setores mais intensivos em mão de obra, em que tem desvantagens nas dotações de fatores em comparação com o Sudeste Asiático e passa a se dirigir a setores mais intensivos em recursos naturais, onde há vantagem em relação ao Sudeste Asiático (ver Perez, 2008).

Quadro 1

Identificação dos setores chave da economia brasileira: 1996, 2000, 2005, 2009*

\begin{tabular}{|c|c|c|c|}
\hline Setores chave em 96 & Setores chave em 00 & Setores chave em 05 & $\begin{array}{c}\text { Setores chave em } \\
2009\end{array}$ \\
\hline & & $\begin{array}{c}\text { Indústria extrativa } \\
\text { mineral }\end{array}$ & $\begin{array}{c}\text { Indústria extrativa } \\
\text { mineral }\end{array}$ \\
\hline Metal-Mecânica & Metal-Mecânica & Metal-Mecânica & Metal-Mecânica \\
\hline Química & Química & Química & Química \\
\hline Têxtil & & & $\begin{array}{c}\text { Transporte, } \\
\text { armazenagem e } \\
\text { correio }\end{array}$ \\
\hline
\end{tabular}

Fonte: Elaboração própria a partir dos dados do IBGE - Matrizes Insumo-Produto e Contas Nacionais. *O ano de 2009 foi estimado utilizando a metodologia desenvolvida por Freitas et al. (2012).

A Tabela 2 apresenta os indicadores de encadeamento a montante e a jusante e auxilia na comparação interna dos setores. Verificamos que a indústria de transformação continua sendo muito importante por consistir no setor que mantém os maiores encadeamentos para trás na economia brasileira. Ademais, apresenta alguns segmentos com importantes encadeamentos para frente. No entanto, será que esses segmentos que continuam importantes mantêm encadeamentos da mesma dimensão?

Percebe-se, na Tabela 2, que minerais não metálicos, metal-mecânica, papel e celulose, têxtil, confecções e outras indústrias decresceram seu nível de encadeamento a montante ao longo do tempo, enquanto eletro-eletrônica e automotiva, borracha e plásticos, químicos e calçados incrementaram o seu encadeamento a montante. Essas mesmas relações, no geral, se incrementaram nos segmentos fora da indústria de transformação. No entanto, a diminuição dos encadeamentos a montante na indústria de transformação não parece ter sido uniforme. Em geral, os segmentos experimentaram seus decréscimos mais intensos entre 1996 e 2000 . Entre 2000 e 2005, a maior parte dos setores apresentou uma pequena recuperação dos seus efeitos de encadeamento. 
Tabela 2

Índices de encadeamento a montante e a jusante,

Brasil, 1996, 2000, 2005, 2009*

\begin{tabular}{|c|c|c|c|c|c|c|c|c|}
\hline & \multicolumn{4}{|c|}{ Encadeamento a Montante } & \multicolumn{4}{|c|}{ Encadeamento a Jusante } \\
\hline & 1996 & 2000 & 2005 & 2009 & 1996 & 2000 & 2005 & 2009 \\
\hline Agropecuária & 1.664 & 1.695 & 1.836 & 1,756 & 2.612 & 2.063 & 2.202 & 2,162 \\
\hline Indústria extrativa mineral & 1.828 & 1.818 & 1.905 & 1,888 & 1.503 & 1.821 & 2.107 & 1,910 \\
\hline Não Metálicos & 2.069 & 2.066 & 2.061 & 2,033 & 1.519 & 1.303 & 1.313 & 1,355 \\
\hline Metal-Mecânica & 2.133 & 2.043 & 2.094 & 2,037 & 3.091 & 2.187 & 2.417 & 2,302 \\
\hline Eletro-Eletrônica e Automotiva & 2.073 & 2.011 & 2.250 & 2,185 & 1.569 & 1.601 & 1.739 & 1,719 \\
\hline Celulose, Papel e Gráfica & 2.213 & 1.938 & 2.019 & 1,946 & 1.797 & 1.782 & 1.621 & 1,547 \\
\hline Borracha e Plásticos & 2.036 & 2.220 & 2.208 & 2,045 & 1.717 & 1.497 & 1.517 & 1,460 \\
\hline Química & 1.965 & 2.156 & 2.175 & 2,066 & 3.960 & 3.794 & 4.067 & 3,519 \\
\hline Têxtil & 2.244 & 1.958 & 1.970 & 1,912 & 2.385 & 1.821 & 1.799 & 1,661 \\
\hline Confecções & 2.227 & 1.883 & 1.968 & 1,879 & 1.013 & 1.049 & 1.032 & 1,029 \\
\hline Calçados & 2.206 & 2.334 & 2.333 & 2,090 & 1.211 & 1.268 & 1.302 & 1,214 \\
\hline Alimentos e Fumo & 2.382 & 2.367 & 2.451 & 2,428 & 1.778 & 1.744 & 1.818 & 1,747 \\
\hline Outros & 1.999 & 1.874 & 1.940 & 1,849 & 1.330 & 1.309 & 1.309 & 1,281 \\
\hline $\begin{array}{l}\text { Produção e distribuição de } \\
\text { eletricidade, gás e água }\end{array}$ & 1.577 & 1.726 & 1.738 & 1,785 & 2.055 & 2.289 & 2.470 & 2,257 \\
\hline Construção & 1.598 & 1.788 & 1.711 & 1,736 & 1.178 & 1.189 & 1.169 & 1,177 \\
\hline Comércio & 1.653 & 1.419 & 1.439 & 1,423 & 2.139 & 2.393 & 2.446 & 2,564 \\
\hline $\begin{array}{l}\text { Transporte, armazenagem e } \\
\text { correio }\end{array}$ & 1.757 & 1.738 & 1.854 & 1,848 & 1.839 & 2.284 & 2.369 & 2,426 \\
\hline Serviços de informação & 1.270 & 1.698 & 1.699 & 1,767 & 1.271 & 1.860 & 1.938 & 1,902 \\
\hline Intermediação financeira & 1.406 & 1.673 & 1.480 & 1,479 & 1.556 & 2.153 & 1.955 & 2,198 \\
\hline Atividades imobiliárias e aluguel & 1.064 & 1.075 & 1.089 & 1,117 & 1.267 & 1.246 & 1.216 & 1,240 \\
\hline Outros serviços & 1.513 & 1.667 & 1.669 & 1,638 & 2.200 & 2.868 & 2.505 & 2,638 \\
\hline $\begin{array}{l}\text { Administração, saúde e educação } \\
\text { públicas }\end{array}$ & 1.419 & 1.504 & 1.524 & 1,490 & 1.308 & 1.124 & 1.101 & 1,093 \\
\hline
\end{tabular}

Com relação ao período entre 2005 e 2009, a queda geral dos encadeamentos que pode ser percebida nos setores industriais pode estar associada à crise e ao arrefecimento do ciclo de commodities. No entanto, o ponto interessante é que essa queda geral no período é acompanhada por um movimento oposto dos setores de serviço que apresentaram intensificação dos encadeamentos entre 2005 e $2009^{6}$.

(6) Dentre os 9 setores de serviços, quatro apresentaram aumento dos encadeamentos a montante e cinco dos encadeamentos a jusante. 
Apenas três setores da indústria de transformação - confecções, calçados e eletro-eletrônica e automotiva - incrementaram seus encadeamentos a jusante. Nesse caso, também, o resultado não é consequência de uma tendência constante, mas de um decréscimo nos primeiros cinco anos, seguido de recuperação nos anos seguintes.

Nassif (2013) utiliza uma agregação de 19 setores para analisar mudanças estruturais a partir de dados de insumo-produto. A Figura 2A (Anexo) apresenta quatro gráficos de dispersão desses $19^{7}$ setores nos quais cada um dos quadrantes representa os grupos de setores classificados de acordo com a relevância do poder de dispersão, no eixo das abscissas, e da sensibilidade de dispersão, no eixo das ordenadas. De acordo com Nassif (2013), o principal movimento que se percebe ao analisar os gráficos de 1996 e 2000 é o aumento dos encadeamentos para frente de setores de serviços, com a migração de três setores do terceiro quadrante para o segundo. Esse movimento vai ao encontro com o que é observado na Figura 1A (Anexo). No período entre 1996 e 2000 houve um aumento do consumo intermediário de serviços por outros setores, o que leva a um aumento dos encadeamentos para frente dos serviços. Esse movimento pode ser atribuído ao processo de terceirização. Já a indústria apresenta uma perda de capacidade de induzir crescimento nesse período, sobretudo com relação aos seus encadeamentos para trás. Ao analisar os quatro gráficos, com ênfase na indústria, percebe-se uma redução dos encadeamentos em 2000 com relação a 1996, uma melhora até 2005 e uma nova recaída entre 2005 e 2009.

Ao comparar os anos de 1996 e de 2009, é possível perceber que, apesar de a indústria ter apresentado um movimento de enfraquecimento dos elos, os setores de serviço, ao longo do período, ganharam encadeamentos de modo que dos seis setores que habitavam o terceiro quadrante, relativo aos setores de baixo encadeamento tanto a jusante quanto a montante, apenas três mantêm a posição, tendo inclusive um deles migrado para o primeiro quadrante relativo aos setores chave.

\section{Discussão e conclusões}

Economistas e acadêmicos vêm se esforçando nos últimos trinta anos para entender os eventos sobre mudança estrutural nas economias em desenvolvimento. Autores vêm acompanhando a série de emprego e valor adicionado sem aparente consenso, mas com a identificação da existência de problemas que estão relacionados com a perda da dinâmica da indústria que até o início da década de 80 se mostrava como o setor que mais crescia na economia brasileira. A reversão dessa

(7) Em Nassif (2013), o setor de Química corresponde à agregação do setor Borracha e Plástico com o setor Química. Já o setor Complexo Têxtil, presente em Nassif (2013), corresponde à agregação do setor Têxtil, setor Calçados e setor Confecções da classificação utilizada no presente trabalho. Os demais setores são equivalentes. 
tendência vem chamando a atenção para a identificação de doenças e obstáculos. É, no entanto, fundamental que haja uma identificação clara dos problemas para não se guiar a economia para caminhos equivocados.

Este trabalho se propôs a realizar uma abordagem um pouco diferente daquela que vem sendo alvo de contemplação pela bibliografia aqui resenhada. $\mathrm{O}$ artigo utilizou, além dos indicadores usuais, a abordagem de insumo-produto para mensurar e verificar a força dinâmica da indústria brasileira. Assim, a aplicação dos índices de Rasmussen-Hirschman não só complementa a caracterização do processo, como qualifica o poder da indústria de induzir o crescimento.

Algumas observações podem ser extraídas desta análise no que se refere ao processo de mudança estrutural pelo qual vem passando a economia brasileira. A primeira é que o argumento de que as importações de produtos intermediários estão tornando os encadeamentos da indústria de transformação no Brasil mais rarefeitos não parece se sustentar como tendência. Nos dados aqui levantados, o crescimento da penetração das importações no Brasil foi algo que prevaleceu na década de 90 , mas revertido em alguns setores ou estabilizado em outros pelo menos até 2009, quando os nossos dados de matrizes se encerram.

A verdade é que o final dos anos 90 coincide com o fenômeno da terceirização das atividades de serviços que se situavam dentro da indústria e parece justificar uma tendência à perda de valor adicionado em relação ao valor da produção da indústria, mas ao mesmo tempo, ao retirar o produto de dentro da indústria, os indicadores de encadeamento para trás seriam potencializados. Assim, a ideia de rarefação das atividades industriais parece ser bastante plausível. Não foi objetivo do trabalho verificar o efeito da taxa de câmbio sobre esses elementos, mas é importante frisar que, embora 1999-2000 sejam anos de câmbio desvalorizado, o período de 1996 a 1998 assistiu uma importante valorização cambial.

No entanto, o período de 2000 a 2005 assistiu uma remontagem relativa das cadeias produtivas. A indústria tornou seus encadeamentos mais densos em média. É interessante perceber, contudo, que o processo de adensamento dos encadeamentos a montante da indústria coincide com um processo de adensamento dos encadeamentos a jusante dos demais segmentos. Pode-se pensar que a indústria de transformação brasileira vem sendo paulatinamente substituída pelos serviços como importante fornecedor do país. A interpretação mais plausível, nesse caso, é de uma destruição definitiva de laços internos à cadeia industrial no período de 1996 a 2000 com o incremento de laços com o segmento de serviços o que, de certa forma, está em consonância com as tendências internacionais. Nesse caso, uma tendência da economia seria o consumo de bens, mas que são produzidos cada vez mais intensamente a partir de serviços intermediários. 
No período entre 2005 e 2009, uma queda dos encadeamentos nos setores industriais é acompanhada por uma melhora dos setores de serviço. A piora da indústria poderia estar associada às consequências para a economia brasileira da crise internacional e do fim do boom de commodities que explica, sobretudo, uma queda de demanda por produtos da indústria extrativa mineral que, por tratar-se de um dos setores chave no período, tem forte impacto sobre a economia.

Ao mesmo tempo, o trabalho permitiu perceber um deslocamento do centro dinâmico da indústria de alguns segmentos mais leves, como a indústria têxtil, para segmentos mais pesados, como a indústria extrativa e mineração. É interessante perceber que o ciclo de commodities baseado na mineração e seguido pela economia brasileira nos anos mais recentes deu lugar a um fortalecimento dos encadeamentos. Fica, portanto, a sugestão de compreender por que esse fortalecimento está se dando e se é possível constituir um processo de aprendizado a partir dos segmentos de base da indústria.

\section{Referências bibliográficas}

BAUMOL, W. Macroeconomics of unbalanced growth: the anatomy of an urban crisis. The American Economic Review, Jun. 1967.

BRESSER-PEREIRA, L. C. The Dutch disease and its neutralization: a Ricardian approach. Brazilian Journal of Political Economy, v. 28, n. 1 (109), Jan./Mar. 2008.

CLARK, C. The conditions of economic progress. London: Macmillan, 1957.

FREITAS, F.; NASSIF, L.; TEIXEIRA, L.; NEVES, J. P. Metodologia de estimação de matrizes insumo-produto para os anos 2000. Rio de Janeiro: Instituto de Economia, GIC, 2012. Mimeografado.

GERSHUNY. The future of service employment. In: GIARINI, O. The emerging service economy. Perganon Press, 1987.

HIRSCHMAN, A. O. The strategy of economic development. New Haven: Yale University Press, 1958.

IEDI. Desindustrialização e os dilemas do crescimento econômico recente. São Paulo: IEDI, nov. 2007. Mimeografado.

Mimeografado.

Ocorreu uma desindustrialização no Brasil? São Paulo: IEDI, nov. 2005.

KALDOR, N. (1966). Causes of the slow rate of economic growth in the United Kingdom. In: KALDOR, N. Further essays on economic theory. New York: Holmes \& Meier, 1978.

LAPLANE, M. F.; SARTI, F. Prometeu acorrentado: O Brasil na indústria mundial no início do século XXI. In CARNEIRO, R. (Org.). A supremacia dos mercados e a política econômica do Governo Lula. São Paulo: Editora Unesp, 2006. 
NASSIF, A. Há evidências de desindustrialização no Brasil? Revista de Economia Política, v. 28, n. 1, 2008.

NASSIF, L. Mudança estrutural na economia brasileira de 1996 a 2009: uma análise a partir das matrizes insumo-produto. Dissertação (Mestrado em Economia) Instituto de Economia, Universidade Federal do rio de Janeiro, Rio de Janeiro. 2013.

OREIRO, J. L.; FEIJÓ, C. A. Desindustrialização: conceituação, causas, efeitos e o caso brasileiro. Revista de Economia Política, v. 30, n. 2 (118), p. 219-232, 2010.

PALMA, J. G. Four sources of deindustrialization and a new concept of the Dutch disease. In: OCAMPO, J. A. (Org.). Beyond reforms. Palo Alto: Stanford University Press, 2005.

PEREZ, C. A Vision for Latin America: a resource-based strategy for technological dynamism and social exclusion. CEPAL, 1998. Mimeografado.

ROCHA, F. Produtividade do trabalho e mudança estrutural nas indústrias brasileiras extrativa e de transformação, 1970-2001. Revista de Economia Política, v. 27, n. 2 (106), 2007.

Composição do crescimento dos serviços na economia brasileira: uma análise da matriz insumo-produto, 1985-1992. Econômica, v. 1 (2), 107-130, 1992. ROSENSTEIN-RODAN, P. Notes on the theory of the 'Big Push'. In: ELLIS, H. (Ed.). Economic development for Latin America. New York: St. Martin's Press, 1957.

ROWTHORN, R; RAMASWANY, R. Growth, trade and deindustrialization. IMF Staff Papers, v. 46, n. 1, 1999.

; D Deindustrialization: causes and implications. In: STAFF

studies for the World Economic Outlook. Washington: International Monetary Fund, 1997.

; WELLS, J. R. De-industrialization and foreign trade. Cambridge: Cambridge University Press, 1987.

SACHS, J. D.; SHATZ, H. J. Trade and jobs in U.S. manufacturing. Brooking Papers on Economic Activity, 1, 1994.

SAEGER, S. Globalization and economic structure in OECD. Ph.D dissertation, Harvard University, 1996.

SYRQUIN, M. Patterns of structural change. In: CHENERY, H.; SRINIVASAN, T. Handbook of development economics. Elsevier, 1988.

YOUNG, A. Increasing returns and economic progress. Economic Journal, 38, p. 527-542, 1928. 


\section{Apêndice}

\begin{tabular}{|c|c|c|c|}
\hline & Agregação com 22 setores & $\begin{array}{c}\text { Agregação com } 43 \\
\text { setores } \\
\end{array}$ & $\begin{array}{c}\text { Agregação com } 55 \\
\text { setores }\end{array}$ \\
\hline \multirow{2}{*}{$\begin{array}{l}\text { Setores } \\
\text { primários }\end{array}$} & Agropecuária & 1 & 101 e 102 \\
\hline & Indústria extrativa mineral & 2 e 3 & 201,202 e 203 \\
\hline \multirow{11}{*}{ 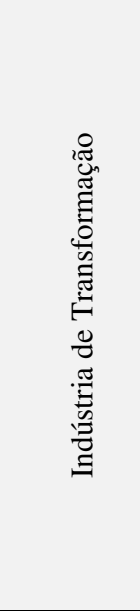 } & Não Metálicos & 4 & 319 e 320 \\
\hline & Metal-Mecânica & 5 ao 8 & 321 ao 324 \\
\hline & Eletro-Eletrônica e Automotiva & 10 ao 13 & $\begin{array}{c}325 \text { ao } 333 \text { exceto } \\
329 \\
\end{array}$ \\
\hline & Celulose, Papel e Gráfica & 15 & 307 ao 308 \\
\hline & Borracha e Plásticos & 16 e 21 & 318 \\
\hline & Química & 17 ao 20 & 309 ao 317 \\
\hline & Têxtil & 22 & 303 \\
\hline & Confecções & 23 & 304 \\
\hline & Calçados & 24 & 305 \\
\hline & Alimentos e Fumo & 25 ao 31 & 301 e 302 \\
\hline & Outros & 14 e 32 & 306,329 e 334 \\
\hline \multirow{9}{*}{$\sum_{\substack{0 \\
\infty}}^{\infty}$} & $\begin{array}{l}\text { Produção e distribuição de } \\
\text { eletricidade, gás e água }\end{array}$ & 33 & 401 \\
\hline & Construção & 34 & 501 \\
\hline & Comércio & 35 & 601 \\
\hline & $\begin{array}{l}\text { Transporte, armazenagem e } \\
\text { correio }\end{array}$ & 36 & 701 \\
\hline & Serviços de informação & 37 & 801 \\
\hline & $\begin{array}{l}\text { Intermediação financeira, } \\
\text { seguros e previdência } \\
\text { complementar }\end{array}$ & 38 & 901 \\
\hline & $\begin{array}{l}\text { Atividades imobiliárias e } \\
\text { aluguel }\end{array}$ & 41 & 1001 \\
\hline & Outros serviços & 39,40 e 43 & 1101 ao 1107 \\
\hline & $\begin{array}{l}\text { Administração, saúde e } \\
\text { educação públicas }\end{array}$ & 42 & 1201,1202 e 1203 \\
\hline
\end{tabular}




\section{Anexo}

Figura 1A

Grupos de setores de acordo com relevância dos índices de Rasmussen-Hirschman - 1996, 2000, 2005 e 2009
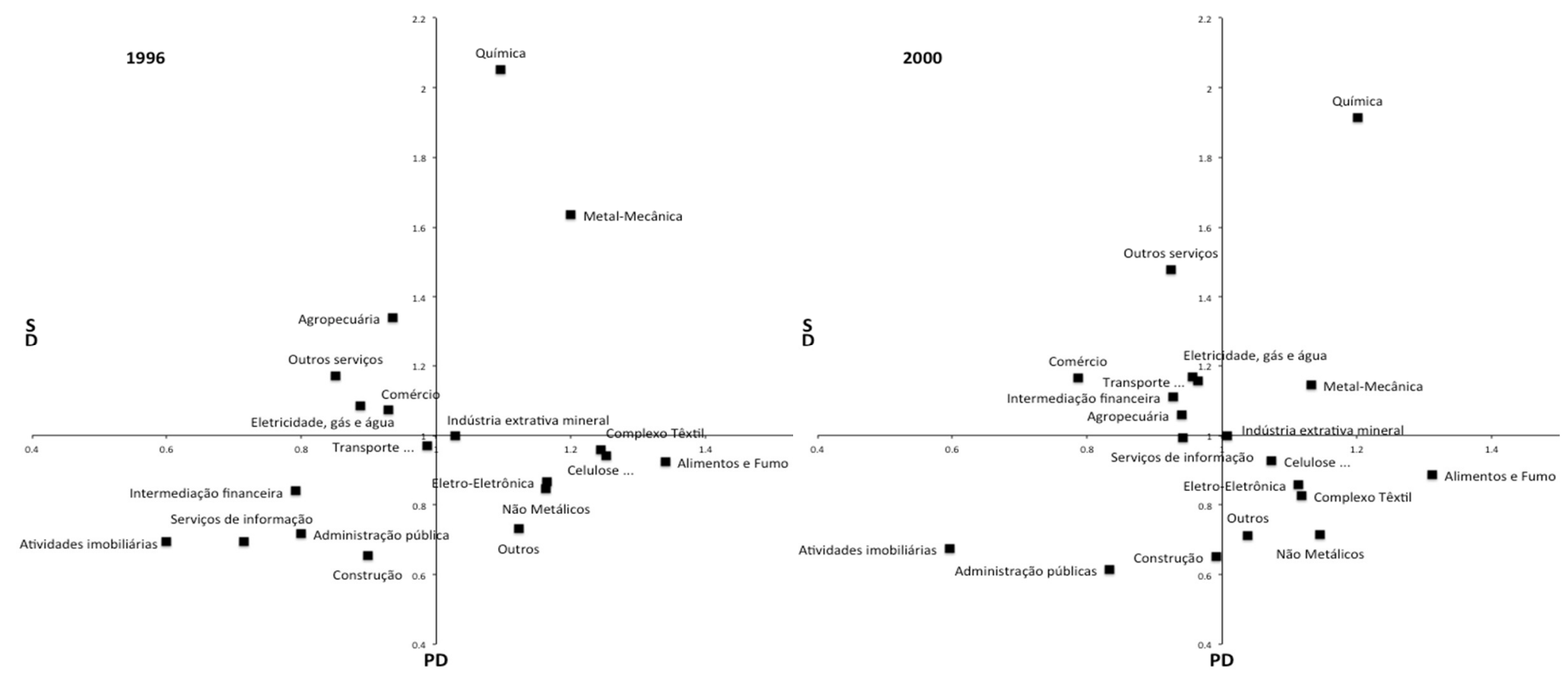


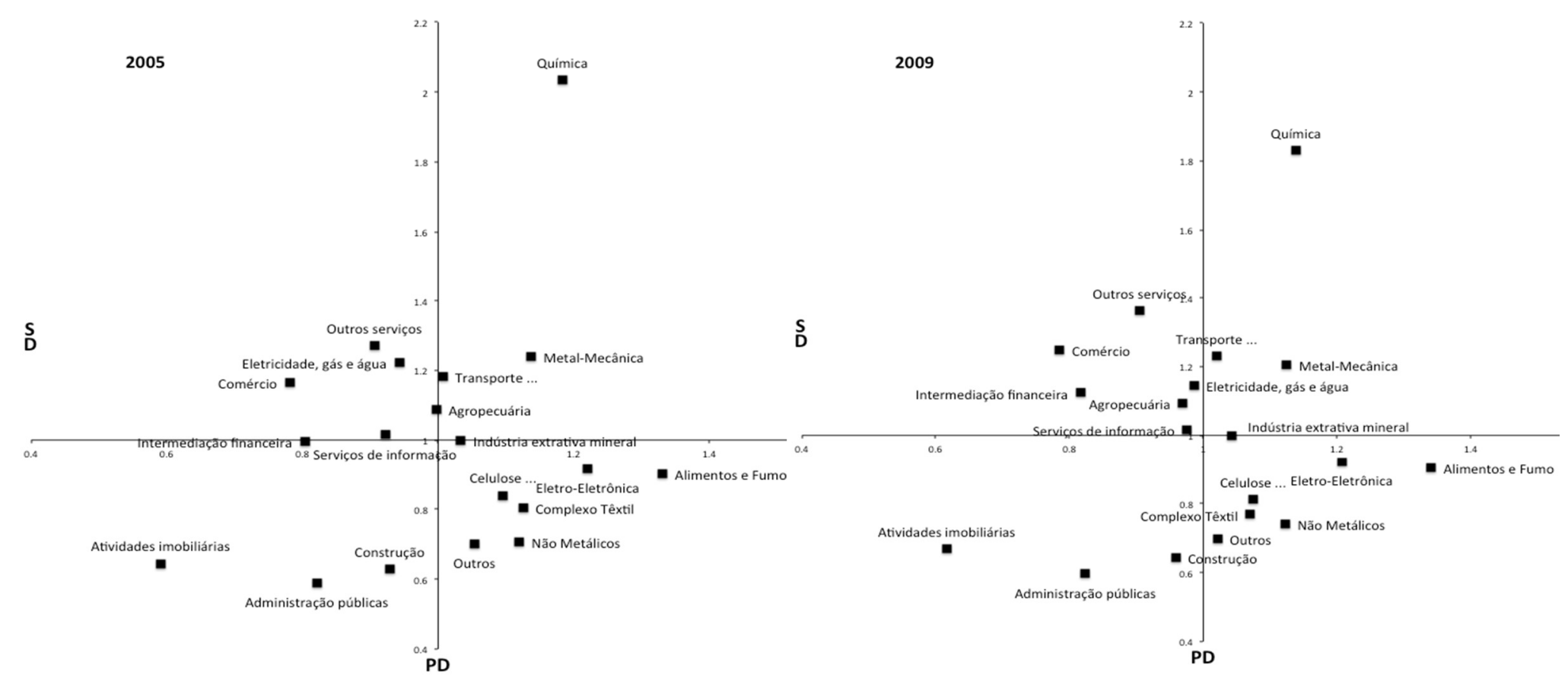

Fonte: Nassif (2013). 